\title{
Bilayer Button Graft for Endoscopic Repair of High-Flow Cranial Base Defects
}

Chris Luminais

Thomas Jefferson University

M. L. Otten

Thomas Jefferson University

A. A. Farag

Thomas Jefferson University

P. Soni

Thomas Jefferson University

Follow this and additional works at: https://jdc.jefferson.edu/otograndrounds W. Mohiuddin

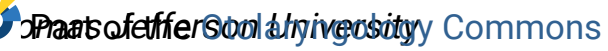

Let us know how access to this document benefits you

See next page for additional authors

Recommended Citation

Luminais, Chris; Otten, M. L.; Farag, A. A.; Soni, P.; Mohiuddin, W.; Ziegler, N.; Nyquist, G. G.;

Farrell, C.; Rosen, M. R.; and Evans, J. J., "Bilayer Button Graft for Endoscopic Repair of High-

Flow Cranial Base Defects" (2015). Department of Otolaryngology - Head and Neck Surgery

Presentations and Grand Rounds. Presentation 38.

https://jdc.jefferson.edu/otograndrounds/38

This Article is brought to you for free and open access by the Jefferson Digital Commons. The Jefferson Digital Commons is a service of Thomas Jefferson University's Center for Teaching and Learning (CTL). The Commons is a showcase for Jefferson books and journals, peer-reviewed scholarly publications, unique historical collections from the University archives, and teaching tools. The Jefferson Digital Commons allows researchers and interested readers anywhere in the world to learn about and keep up to date with Jefferson scholarship. This article has been accepted for inclusion in Department of Otolaryngology - Head and Neck Surgery Presentations and Grand Rounds by an authorized administrator of the Jefferson Digital Commons. For more information, please contact:

JeffersonDigitalCommons@jefferson.edu. 


\section{Authors}

Chris Luminais, M. L. Otten, A. A. Farag, P. Soni, W. Mohiuddin, N. Ziegler, G. G. Nyquist, C. Farrell, M. R. Rosen, and J. J. Evans 


\title{
Bilayer Button Graft for Endoscopic Repair of High-Flow Cranial Base Defects
}

\section{Jefferson}

\author{
Otten ML, Farag AA, lloreta AM, Soni P, Luminais C, Mohiuddin W, Ziegler N, \\ Nyquist GG, Farrell C, Rosen MR, Evans JJ
}

\section{Introduction}

Closure of dural defects in trans-nasal, extended, endoscopic techniques remains a challenge, and published cerebrospinal fluid (CSF) leak rates are higher than rates for trans-cranial approaches. Development of a technique that used a vascularized, nasoseptal flap (NSF) significantly reduced the rate of CSF leak, and several groups have developed ways to buttress the NSF. A closure technique developed at our institution uses a bilayer "button" of fascia lata. The initial series of twenty patients repaired with this method from 2007 to July 1, 2009 were presented, with a CSF leak rate of 10\% (Luginbuhl et al 2010).

\section{Methods}

We reviewed cases between July $1^{\text {st }}$, 2009 through January $31^{\text {st }}$, 2014. These patients had high flow leaks, which involved openings into a cistern or ventricle. The included patients had a primary "button" graft, which was constructed from a fresh piece of fascia lata. The inlay portion was $25-30 \%$ larger than the defect, and the onlay portion was 5-10\% larger than the defect. The two pieces were sutured together with two to four, 4-0 Neurolon sutures (Ethicon, Bridgewater, NJ). They were then inserted in the subdural and epidural spaces, forming a water-tight seal.

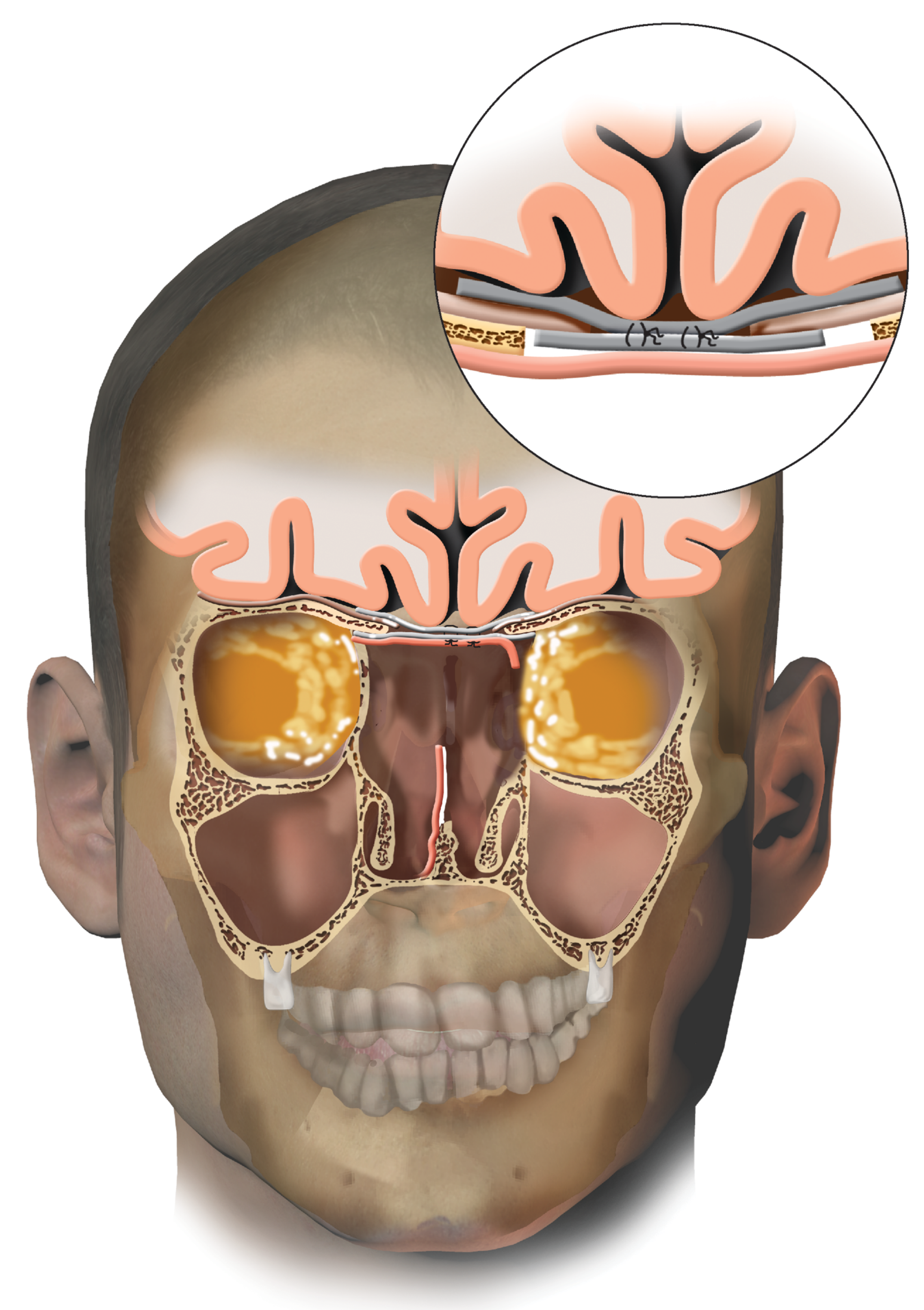

Figure 1: Bilayer button graft closure of the anterior cranial base with a nasoseptal flap

\section{Results}

Of the sixty-six cases that had button graft placement, seven (11\%) did not have a NSF, and none of these leaked. There were two (3\%) patients who had postoperative leaks. The population characteristics included an average age of 54 years and an average Body Mass Index of 30. In 59/66 (89.4\%) of cases, a nasoseptal flap was placed. Anterior skull base meningiomas represented $29 \%$ of the pathology, craniopharyngiomas were $27 \%$, macroadenomas were $15 \%$, esthesioneuroblastomas were 6\%, and Rathke's cleft cysts were also $6 \%$. Lumbar drains were placed at surgery in only $9 / 66$ (13.6\%) cases, and average length of stay was six days.

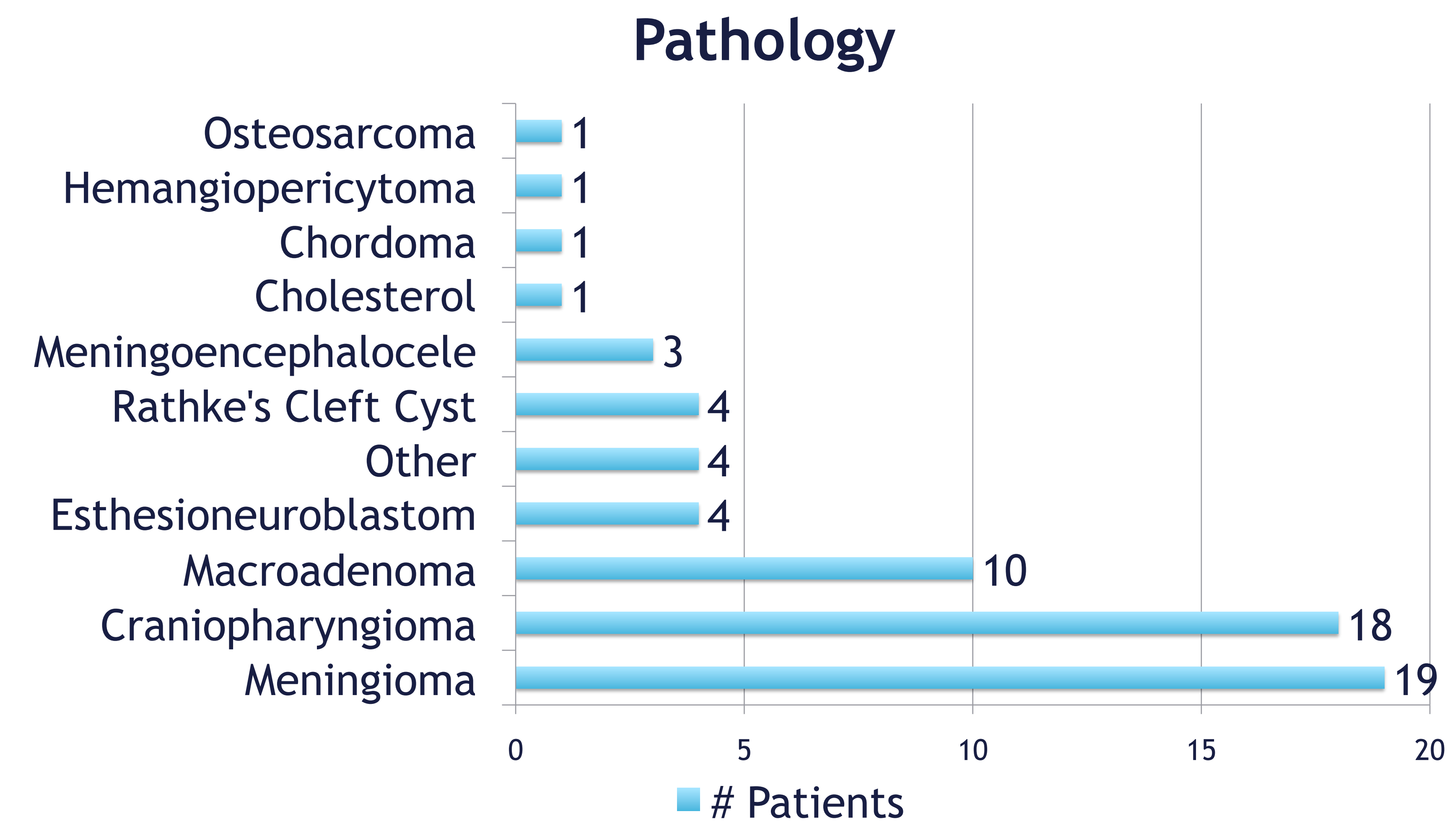

Surgical Locations
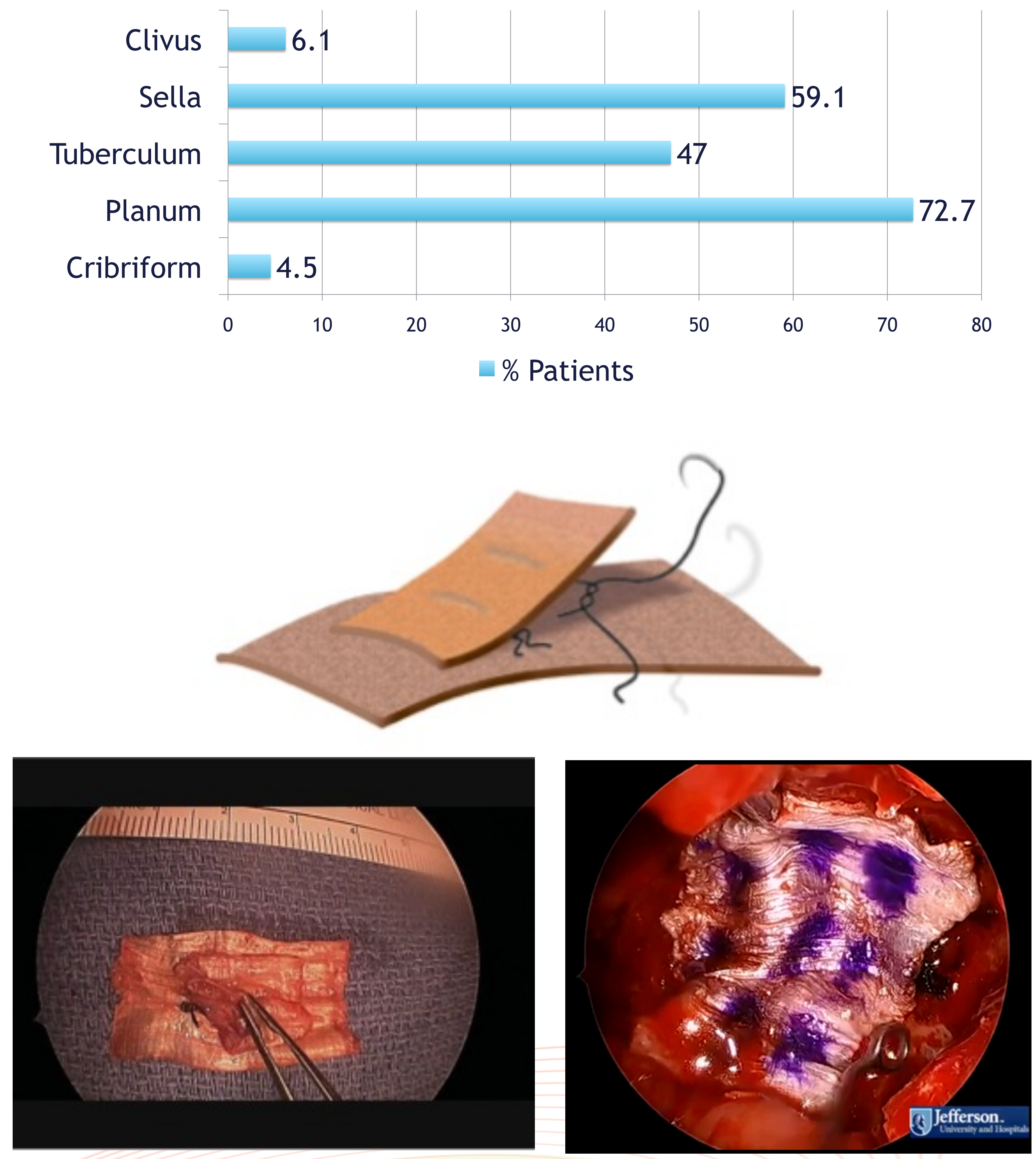

Figure 2: Illustration (top) and intraopperative (bottom) pitures of the bilayer button graft

\section{Discussion}

The bilayer button graft was used successfully to repair large skull base defects with high-flow CSF leaks. The button graft has a low (3\%) rate of postoperative CSF leak, which is comparable to leak rates reported for other techniques, such as the gasket seal (GarciaNavarro et al 2011). Of the two cases that had postoperative leaks, one was a revision of a Rathke's cleft cyst and the other was a meningioma; both cases involved the tuberculum. Notably, $47 \%$ of cases involved the tuberculum, a region that can be difficult to close. This area remains challenging, but it is our belief that the flexible composition of the bilayer button graft allows it to be placed more easily and successfully in the angle of the tuberculum.
Complications

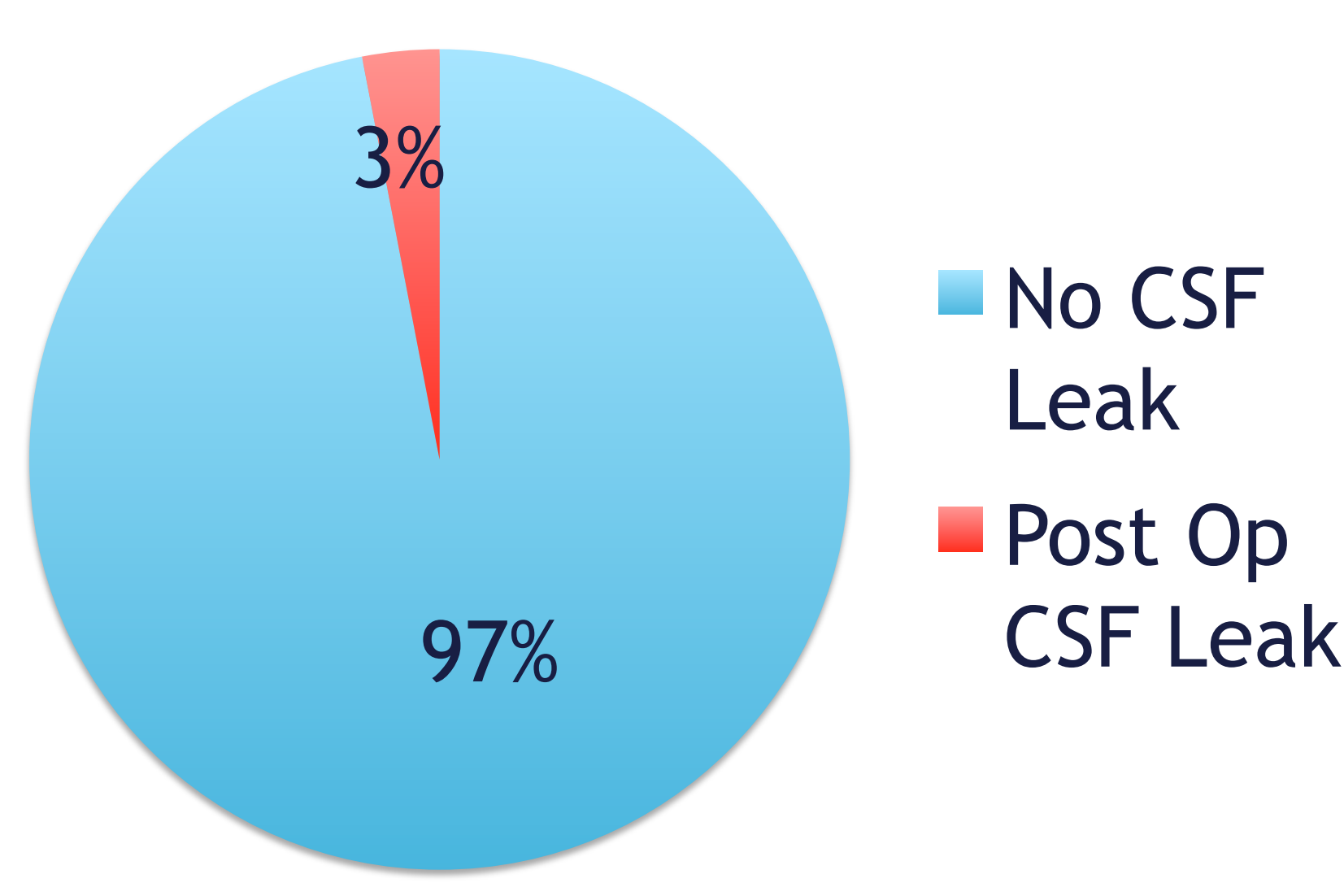

Nasoseptal Flap

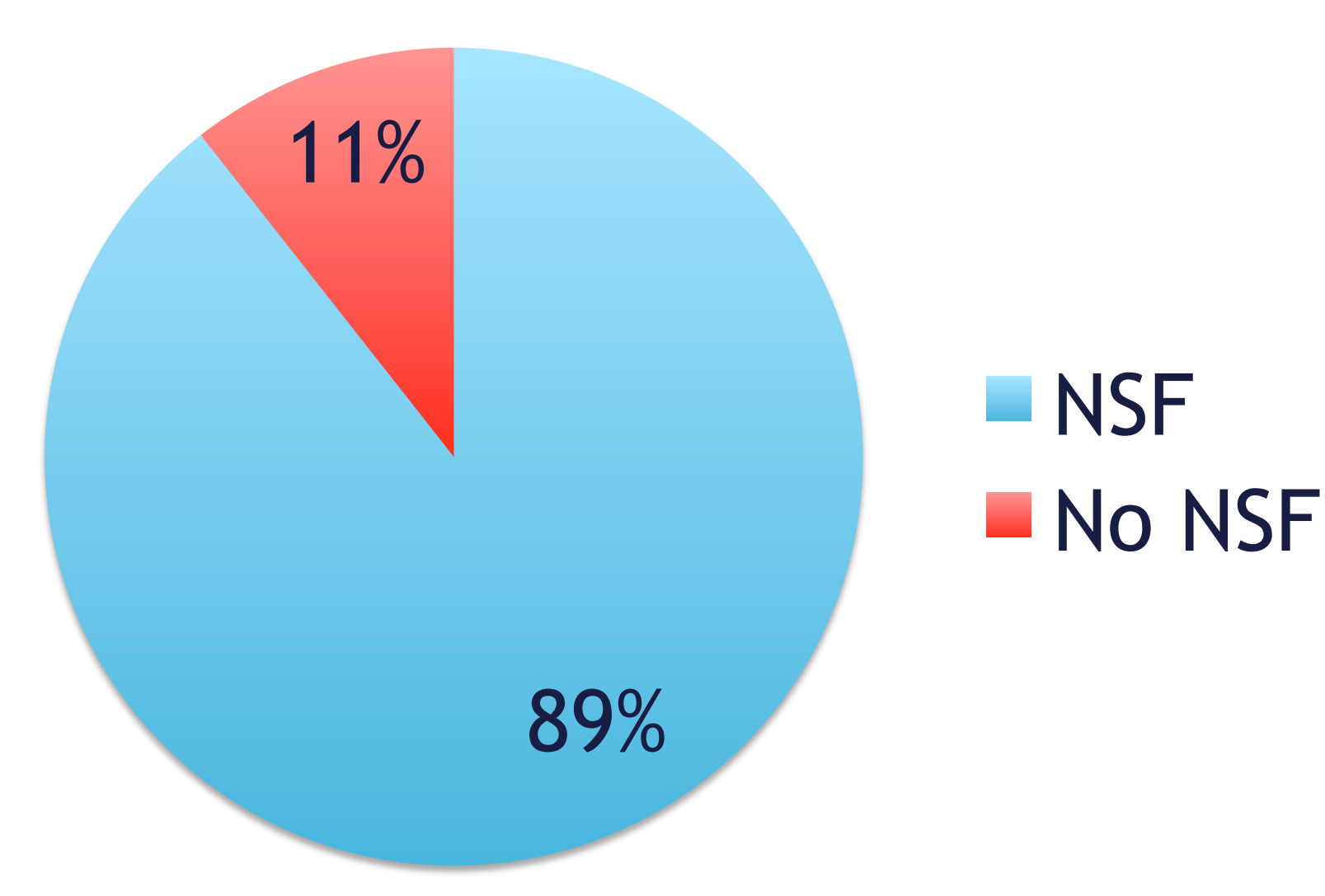

\section{Conclusions}

The bilayer button graft is a useful supplement to the nasoseptal flap in trans-nasal, endoscopic, skull base surgery. It can be used to close large defects that involve high-flow leaks. Furthermore, our CSF leak rate is comparable to that reported for trans-cranial approaches.

\section{References}

Luginbuhl, A. J., Campbell, P. G., Evans, J., \& Rosen, M. (2010). Endoscopic repair of high-flow cranial base defects using a bilayer button. The Laryngoscope, 120(5), 876-880.

Garcia-Navarro, V., Anand, V. K., \& Schwartz, T. H. (2011). Gasket seal closure for extended endonasal endoscopic skull base surgery: efficacy in a large case series. World neurosurgery.

\section{Contact Information}

Dr. Marc R. Rosen: Marc.Rosen@jefferson.edu

Dr. James Evans: James.Evans@jefferson.edu 